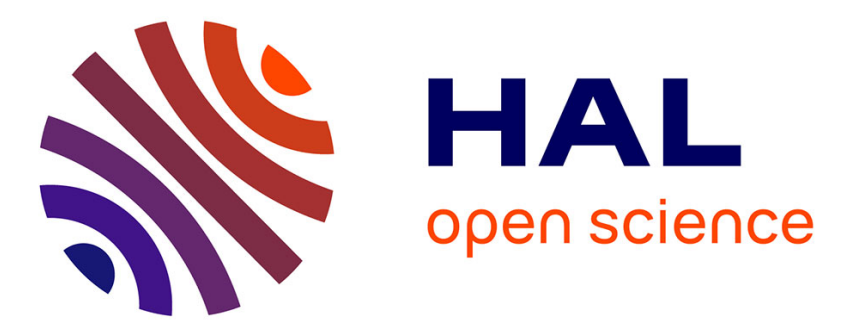

\title{
Attrition-induced spontaneous chiral amplification of the $\gamma$ polymorphic modification of glycine
}

\author{
Arkadii V. Tarasevych, Alexander E. Sorochinsky, Valery P. Kukhar, Loic \\ Toupet, Jeanne Crassous, Jean-Claude Guillemin
}

\section{- To cite this version:}

Arkadii V. Tarasevych, Alexander E. Sorochinsky, Valery P. Kukhar, Loic Toupet, Jeanne Crassous, et al.. Attrition-induced spontaneous chiral amplification of the $\gamma$ polymorphic modification of glycine. CrystEngComm, 2015, 17 (7), pp.1513-1517. 10.1039/C4CE02434F . hal-01107558

\section{HAL Id: hal-01107558}

\section{https://hal-univ-rennes1.archives-ouvertes.fr/hal-01107558}

Submitted on 2 Feb 2015

HAL is a multi-disciplinary open access archive for the deposit and dissemination of scientific research documents, whether they are published or not. The documents may come from teaching and research institutions in France or abroad, or from public or private research centers.
L'archive ouverte pluridisciplinaire HAL, est destinée au dépôt et à la diffusion de documents scientifiques de niveau recherche, publiés ou non, émanant des établissements d'enseignement et de recherche français ou étrangers, des laboratoires publics ou privés. 


\title{
Attrition-induced spontaneous chiral amplification of the $\gamma$ polymorphic modification of glycine
}

\author{
Arkadii V. Tarasevych, ${ }^{* a, b, c}$ Alexander E. Sorochinsky ${ }^{\mathrm{b}}$, Valery P. Kukhar ${ }^{\mathrm{b}}$, Loïc Toupet ${ }^{\mathrm{d}}$, Jeanne \\ Crassous, $*$ d Jean-Claude Guillemin*a
}

Received (in XXX, XXX) Xth XXXXXXXXX 200X, Accepted Xth XXXXXXXXX 200X

First published on the web $X$ th $X X X X X X X X X 200 X$

DOI: $10.1039 / \mathbf{b 0 0 0 0 0 0 0 0 x}$

Glycine is the simplest achiral amino acid that undergoes spontaneous mirror symmetry breaking when it crystallizes in its chiral $\gamma$-polymorphic modification. As a result of Ostwald ripening, its racemic mixture stochastically becomes optically active. The sense of the resulting handedness can be controlled by addition of one enantiomer of a simple chiral amino acid, the alanine.

\section{Introduction}

Proteinogenic chiral amino-acids all possess the $\mathrm{L}$ configuration and this single handedness is considered as the hallmark of the living world (homochirality). Among the plausible explanations for the origin of such homochirality is the formation of a slight enantiomeric excess that may be increased by an amplification process. ${ }^{\text {la }}$ Stochastic "mirrorsymmetry breaking" that may occur during a crystallization process is among the possibilities for the emergence of a chiral bias in the statistical distribution of optical isomers. ${ }^{1 b}$

Crystallization-induced asymmetric transformations of chiral organic compounds are among the most appealing methodologies for getting pure enantiomers from racemates or scalemic mixtures., ${ }^{2,3}$ More particularly, asymmetric transformations of interconvertible enantiomers forming conglomerates can theoretically provide $100 \%$ yield of the desired enantiomer. Beside the asymmetric transformations of chiral interconverting molecules, ${ }^{4-6}$ the phenomenon of spontaneous mirror symmetry breaking in chiral crystals of achiral substances can be encountered, such as for example in the striking and intensively studied crystallization of sodium chlorate and bromate, ${ }^{7}$ for which the attrition-induced spontaneous chiral amplification (AISCA) phenomenon has been demonstrated. ${ }^{10}$ The process of matter exchange between two phases leading to the loss of asymmetry in one of the phases can be regarded as racemization. The mechanism of spontaneous chiral amplification involves (i) interconversion between antipodal crystals due to the equilibrium with the liquid phase, alongside with (ii) so-called Ostwald ripening in the solid phase (growing of larger crystals at the expense of smaller ones). The autocatalytic enantioselective nucleation leads to the gradual evolution of the crystal optical purity up to the homochiral state.

Glycine is the simplest amino acid which, in contrast to all other proteinogenic amino acids, does not contain substituent at the $\alpha$-carbon and, as a consequence, is achiral. In the crystalline state it can exist in several polymorph modifications: $\alpha, \beta$ and $\gamma$ under ambient conditions and $\beta^{\prime}, \delta, \varepsilon$ and $\zeta$ under high pressure. ${ }^{11}$ Among them $\gamma$ polymorphic modification crystallizes in enantiotopic space groups $P 3_{1}$ and $P 3_{2}$. In spite of the numerous studies in crystallography devoted to the different aspects of glycine modifications including recent single crystal analysis of its gamma form and correlation between its absolute structure and optical rotation, ${ }^{12}$ no attempts have been done to achieve its homochirality. Moreover it has been reported that $\gamma$-Gly is a very promising material for non-linear optical (for second harmonic generation) and piezoelectric applications; its mixed crystals revealed ferroelectric properties. ${ }^{13}$ Here we study spontaneous and induced increases of optical activity in the $\gamma$ Gly crystalline phase using solid state circular dichroism.

\section{Results and discussion}

$\gamma$-Gly was obtained according to the described method of Srinivasan et al. through its crystallization from an aqueous sodium chloride solution (see ESI). ${ }^{14}$ The crystal structure of $\gamma$ polymorphic modification has been confirmed by powder Xray diffraction (see Figure S1). In the recent paper of Chongprasert et al. ${ }^{11 \mathrm{~b}}$ it was demonstrated that depending on the conditions (temperature, concentration, rate of cooling and crystallization), the crystallization of aqueous solutions of glycine can provide any of its three modifications $(\alpha, \beta, \gamma)$ or a mixture of them. The thermodynamic stability of these forms is decreasing in the order $\gamma>\alpha>\beta,{ }^{11 \mathrm{~b}}$ however during crystallization from aqueous solutions its $\alpha$ modification forms faster.

In the initial experiments our goal was to determine the specific value of circular dichroism (CD) in the solid state. During the slow crystallization of glycine from $\mathrm{NaCl}$ solution without stirring, the majority of obtained single crystals revealed CD signal around $210 \mathrm{~nm}$ with random distribution of levo and dextrorotary forms while the whole crop had no optical activity (Table S1, entries 1-7). This result agrees well with former studies. ${ }^{6 \mathrm{c}, 7 \mathrm{a}, 7 \mathrm{c}, 7 \mathrm{f}, 8}$

It is noticeable that the specific ellipticity (mdeg/mg) changed its absolute value from crystal to crystal under the same conditions of measurements (entries 2-7). Some of crystals had zero CD signal (entry 1). The highest values of CD signals obtained for individual crystals reached |40.2| $\mathrm{mdeg} / \mathrm{mg}$ (entry 6). Presumably, the inconstancy of the CD signals can be caused by the epitaxial nature of $\gamma$-Gly conglomerate, namely by simultaneous presence within individual crystals of enantiopure domains of both 


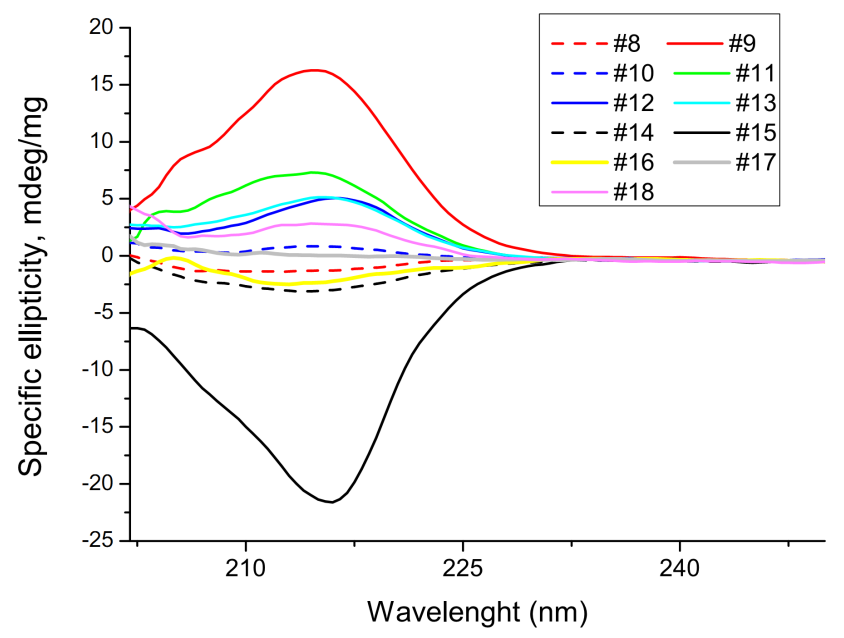

Fig. 1 Solid state circular dichroism of 11 individual crops of $\gamma$-glycine obtained under intensive stirring.

enantiomorphous $l$ and $d$ forms grown together. On the other hand, several years ago Ishikawa et al. reported that besides optically active crystals, $\gamma$-Gly can form monohedral twinning form. ${ }^{12}$ An attempt of distinguishing between levo and dextrorotary crystals of $\gamma$-Gly visually using a polarizing microscope failed. Furthermore, X-ray crystallographic studies on a micro-source $\mathrm{Cu}$ diffractometer of several selected single crystals obtained under these conditions all displayed the $P 3_{1}$ space group (see ESI).

Our further experiments on the crystallization of $\gamma$-Gly were conducted under intensive stirring of the solution (see Table S1, entries 8-18). Figure 1 represents the results of 11 independent crystallizations. In 4 experiments we observed the formation of levorotary form of $\gamma$-Gly (Table S1, entries 8 and 14-16); 6 crystallizations shown positive CD signals (entries 9-13 and 18) and one of the 11 crops virtually had no optical activity (entry 17).

The distribution histogram (Figure 2) of the specific ellipticities for the crops obtained under intensive stirring (Figure 1, see also ESI, Table S1, entries 8-18) corresponds to a feebly marked bimodal symmetrical distribution centered at $0^{\circ}$ and having two peaks around $\pm 3 \mathrm{mdeg} / \mathrm{mg}$. Similar distribution shape has been observed by Kondepudi et al. in 10 independent crystallizations of 4,4'-dimethylchalcone under intensive stirring. ${ }^{8}$ Kaptein et al. demonstrated the possibility of deracemization of an epitaxial racemate. ${ }^{4}$ Obviously in our case better fitting the conditions for the chiral ripening of the solid phase (temperature, time, and intensity of crushing of crystals) might lead to a more pronounced bimodal shape of the histogram.

It can be predicted that in "ideal" experiments when the complete ripening is accomplished during a relatively short time, the distribution is degenerating into the equiprobable obtaining of either of the $\gamma$-glycine pure enantiomorphs. To verify this hypothesis, the next series of experiments on the emergence of solid-state single chirality of $\gamma$-glycine was conducted under the conditions of attrition enhanced grinding using glass beads. In the previous works devoted (i) to mirror symmetry breaking of achiral substances, ${ }^{10}$ and (ii) to

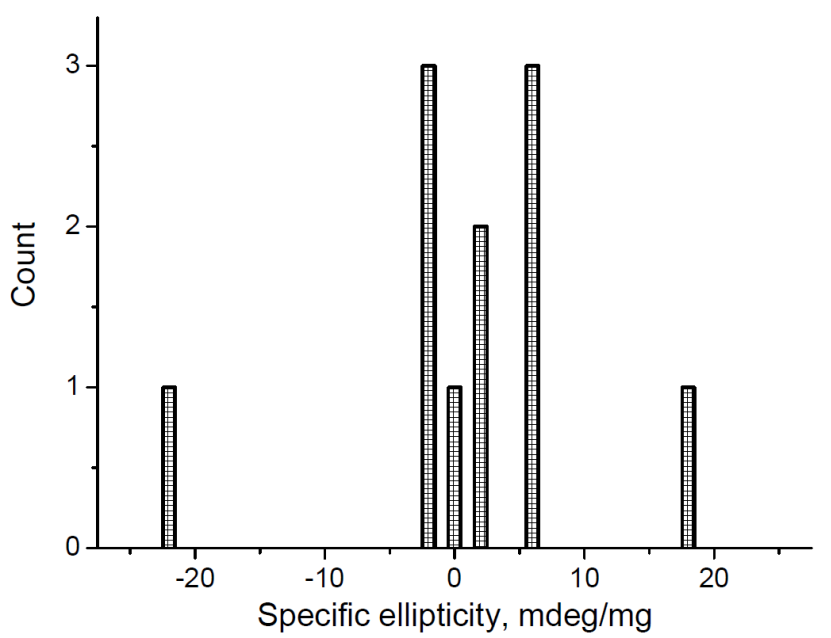

Fig. 2 Histogram of the CD signals of $\gamma$-Gly crops obtained under stirring.

deracemization or enhancement of optical purity of nonracemic mixtures of conglomerates of racemizing enantiomers (asymmetric transformations of enantiomers of the second kind $)^{5}$ it was found that the effectiveness of mechanical crushing of crystals and, as a result, the rate of enhancement of optical purity can be considerably increased using glass beads. The presence of glass beads facilitated the input of energy to the heterogeneous system at the expense of mechanical grinding. In one of the first trials on the attrition enhanced grinding the starting mixture did not change its optical activity and in 10 days of ripening did not reveal any detectable CD signal. However in the further independent experiments we managed to observe the phenomenon of spontaneous symmetry breaking between levo and dextrorotary forms of $\gamma$-glycine. Starting from the optically inactive mixture with the equivalent content of both antipodes, the solid phase of the heterogeneous system by an accident choice evolved from $0 \mathrm{mdeg} / \mathrm{mg}$ up to a virtually constant value of the specific ellipticity (Figure 3, CD bands in color). A sharp rise of the optical activity was observed on the $3^{\text {rd }}$ day of grinding and made eventually up to about $70 \mathrm{mdeg} / \mathrm{mg}$ (Table S1, entry 19). We supposed that the final value of CD signal corresponds (or at least is very close) to the $100 \%$ of the enantiomorphous excess. $\$$ The Figure 3 (the negative CD bands) represents the evolution of homochirality during 9 days. The analysis of the obtained data in the coordinates "time - specific ellipticity" (at a selected wavelength $\sim 210$ $\mathrm{nm})$ gave a curve of the sigmoidal shape which is very close to the Bolzmann type (Figure S2), that points out the pronounced autocatalytic character of the process of evolution of single handedness.

In the next 3 independent ripening experiments using glass beads starting from the same optically inactive material we confirmed the stochastic behavior of the asymmetric amplification (Figure 3, black dotted curves, Table S1: entries 20-22). The grinding was stopped on the $2^{\text {nd }}$ day for $C D$ measurements. Although the experiments were conducted under similar conditions, the resulted optical activity was different: one of the mixtures had been virtually unchanged (entry 22) and 2 others revealed some positive CD signals 


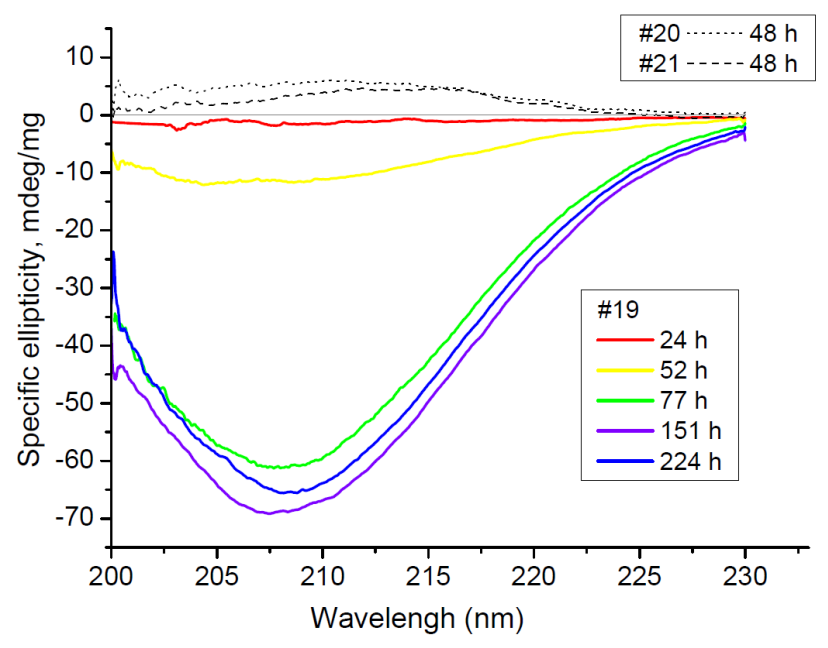

Fig. 3 The evolution of optical activity as a result of Ostwald ripening under the attrition-enhanced conditions using glass beads.

(entries 20-21).

Finally we demonstrated the possibility to control the handedness of the obtained $\gamma$-Gly by means of addition of small amounts ( $5 \%$ by weight) of enantiopure $\mathrm{L}$ and $\mathrm{D}$ alanine under the conditions of intensive stirring with glass beads. Figure 4 represents the results of the asymmetric induction: the spectra of enantiopure L-Ala (dotted curve) and its mixtures with $\gamma$-Gly in the course of the crystal enantiomorphic excess evolution are drawn in red; the corresponding negative $\mathrm{CD}$-active band centered around 210 $\mathrm{nm}$ induced by D-Ala are in blue; the spectrum of the optically inactive $\gamma$-glycine which was used for the experiments is in black. The starting mechanical mixture of the racemic $\gamma$-glycine together with $5 \%$ by weight of L-Ala showed weak CD signal $>10 \mathrm{mdeg} / \mathrm{mg}$, which was caused by the presence of $5 \%$ of enantiopure alanine $\left(\lambda_{\max } \sim 214 \mathrm{~nm}, \theta=\right.$ $55 \mathrm{mdeg} / \mathrm{mg}$ ). After 20 hours of the ripening in the abovementioned conditions (in the saturated solution of glycine in aqueous sodium chloride, $100 \mathrm{~g} / \mathrm{L}$ ) the magnitude of the specific ellipticity made up $34 \mathrm{mdeg} / \mathrm{mg}$. 45 hours later starting from the beginning of the process, the optical activity of the mixture had almost reached its maximal value (79 $\mathrm{mdeg} / \mathrm{mg}$ ), which was just slightly increased $(81 \mathrm{mdeg} / \mathrm{mg}$ ) in one day of grinding. Noteworthy, the subtraction of the starting ellipticity from the final one $\left(\theta_{69 \mathrm{~h}}-\theta_{0}\right)$ gives us the value $(\sim 71 \mathrm{mdeg} / \mathrm{mg})$ corresponding to the maximum $\mathrm{CD}$ signal on the Figure 3 (70 mdeg/mg, Table S1, entry 19) which confirms the enantiomorphic purity of the obtained samples in the experiments of both type (spontaneous chiral symmetry breaking and Ala induced). In the case of induction with D-Ala, the substraction resulted in somewhat higher value $\left(\theta_{69} \mathrm{~h} 76 \mathrm{mdeg} / \mathrm{mg}\right)$, what however lies in the range of the $6 \%$ experimental error.

As far back as at the end of XIX century Kipping and Pope reported data on the enantioselective crystallization of sodium chlorate $\left(\mathrm{NaClO}_{3}\right)$ from the solution of D-glucose, ${ }^{15}$ what has been recently carefully re-checked by Alexander: it turned out that the key role should be rather assigned to the residual chiral nucleus of the inductor. ${ }^{16}$ Similar phenomenon was

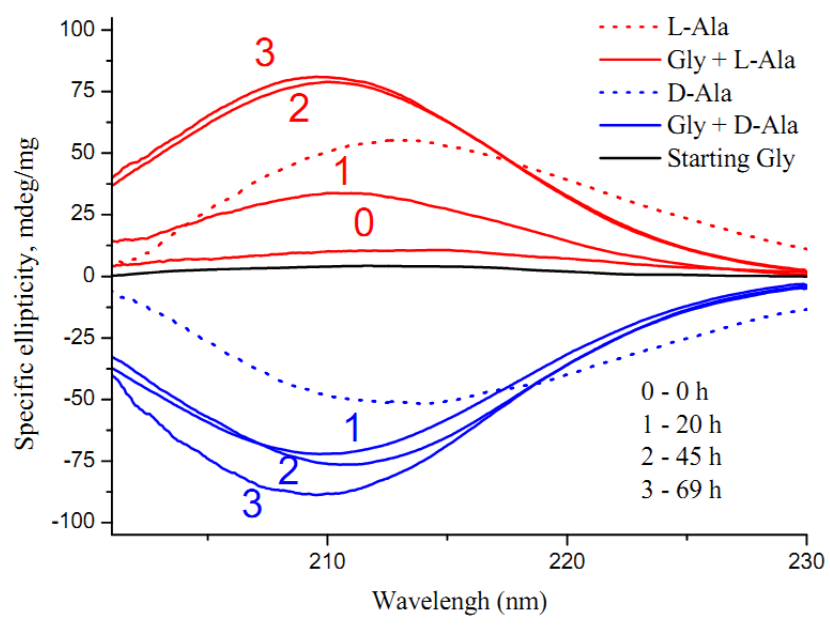

Fig. 4 The induction of asymmetry in $\gamma$-Gly crystals by means of addition of L-(+) (red) and D-(-) (blue) alanines starting from optically inactive $\gamma-$ Gly (black).

observed by Cheung and Cuccia for the directed mirror symmetry breaking of achiral ethylenediammonium sulfate forming chiral crystals (tetragonal enantiotopic space groups $P 4_{1}$ and $P 4_{3}$ ): its transition to solid-state single chirality can be induced by a diversity of enantiopure $\alpha$-amino acids. ${ }^{17}$

We think, that in our experiments on the alanine-directed chiral amplification, the same effect takes place: the crystals of enantiopure L-(+) or D-(-) alanine serve as chiral seeds for the growth of enantiomorphic $(+)$ or $(-)$ forms of $\gamma$-Gly respectively. It should be noted that $\mathrm{L}-(+)$-Ala causes evolution in the direction of $(+)-\gamma$-Gly handedness and vice versa: D-(-)-Ala - induced formation of (-)- $\gamma$-Gly batches. The enantioselective oriented growth of $\gamma$-glycine crystals on the chiral surfaces of alanine can be regarded as a classical epitaxial mechanism. Despite the fact that the crystal lattices of enantiopure alanine and $\gamma$-glycine are not isostructural (L and D-Ala crystallizes in the orthorhombic system, group $P 2,2,2,{ }^{18}$ and $\gamma$-Gly in one of the trigonal enantiomorphic $P 3$ and $P 3_{2}$ groups) this explanation cannot be excluded. The observations reported a few months ago by Niinomi et al. speak in favour of such non-isostructural asymmetric polymorphic transformation. ${ }^{19}$ Another analogy can be drawn to the enantioselective occlusion of racemic natural amino acids into the enantiotopic facets of achiral $\alpha$ polymorphic modification of glycine. As a result of the observed affinity between the hemihedral facet of $\alpha$-glycine (010) to Denantiomers, and $(0 \overline{\mathrm{I}} 0)$ to $\mathrm{L}$ respectively, Lahav et al. with colleagues observed preferential orientation of $\alpha$-Gly crystals on the «solution - air» interface, which resulted in amino acid enantioenrichement in solution. ${ }^{20}$ One more non-classical mechanism - enantiomer-specific oriented attachment, has been recently described by Viedma, Cintas et al. ${ }^{21}$

\section{Conclusions}

We have observed that slow crystallization of $\gamma$-polymorphic modification of glycine without stirring gave well shaped single crystals that in most cases had some optical activity, either (+) or (-). The whole crop had $0^{\circ} \mathrm{CD}$ signal. 11 
independent crystallizations under stirring revealed stochastic generation of batches enriched with either enantiomorphic crystals, the distribution being bimodal. Applying mechanical grinding with glass beads in several parallel crystallizations revealed a phenomenon of attrition-induced spontaneous chiral amplification leading eventually to a homochiral batch. This behavior has a stochastic nature. Moreover addition of one alanine enantiomer causes controlled emergence of homochirality in the $\gamma$-glycine crystalline phase.

The easiness and inclination of glycine for the spontaneous emergence of single handedness should draw attention to the solid state chemistry of this simplest amino acid and to the reassessment of its role in the origin of biological homochirality.

\section{Acknowledgements}

The authors are grateful to Isabelle Marlart for the powder XRD measurements (Institut des Sciences Chimiques de Rennes, Chimie du Solide et Matériaux), to Dr. Elisabeth Le Rumeur for providing the CD facilities (IFR140 facility Biosit, Université de Rennes 1) and to Dr. Yann Trolez for his kind help. Funding supports were received from the Centre National d'Etudes Spatiales (CNES), the PID EPOV (INSUCNRS), from the Centre franco-ukrainien de coopération universitaire et scientifique (CFUCUS) and the Ministry of Education and Science of Ukraine (project DNIPRO 28318QA, grant № M/164-2014). JC acknowledges the ANR10-BLAN-724-1-NCPCHEM.

\section{Notes and references}

${ }^{a}$ Institut des Sciences Chimiques de Rennes, Ecole Nationale Supérieure de Chimie de Rennes, CNRS, UMR 6226, 11 Allée de Beaulieu, CS50837, 35708 Rennes Cedex 7, France. Fax: (+33) 2-23-23-81-08; E-mail: jeanclaude.guillemin@ensc-rennes.fr

${ }^{b}$ Institut of Bioorganic Chemistry and Petrochemistry, National Academy of Sciences of Ukraine, Murmanska Street 1, 02660 Kyiv 94, Ukraine

${ }^{c}$ Boreskov Institute of Catalysis, Siberian Branch of the Russian Academy of Sciences, pr. Akademika Lavrentieva 5, 630090 Novosibirsk, Russia.E-mail: arkadii.v.tarasevych@catalysis.ru

${ }^{d}$ Institut des Sciences Chimiques de Rennes, UMR 6226, Institut de Physique de Rennes, UMR 6251, Université de Rennes 1, CNRS, Campus de Beaulieu, 35042 Rennes Cedex, France. Fax: (+33) 2-23-23-69-39; Email: jeanne.crassous@univ-rennes1.fr

$\dagger$ Electronic Supplementary Information (ESI) available: Table with the values of specific ellipticity and calculated enantiomorphic excess. See DOI: $10.1039 / \mathrm{b} 000000 \mathrm{x} /$

\$ Although Durand et al. used the term "crystal enantiomeric excess", since $l$ and $d$ crystals of achiral crystals cannot be called enantiomers we will further use more correct concept "enantiomorphous excess".

1 (a) I. Weissbuch and M. Lahav, Chem. Rev., 2011, 111, 3236-3267;

(b) G. H. Wagnière. On Chirality and the Universal Asymmetry:

Reflections on Image and Mirror Image, Wiley-VCH\&VHCA, Zürich, Weinheim, 2007.

2 (a) J. Jacques, A. Collet and S. H. Wilen. Enantiomers, Racemates, and Resolutions, Wiley, New York, 1981, ch. 6, pp. 369-373; (b) E. L.

Eliel, S. H. Wilen and L. N. Mander, Stereochemistry of Organic Compounds, Wiley, New York, 1994, ch. 7e, pp. 315-322.

3 (a) D. B. Amabilino and R. M. Kellogg, Isr. J. Chem., 2011, 51, 1034-1040; (b) G. Levilain and G. Coquerel, CrystEngComm, 2010, 12, 1983-1992.

4 B. Kaptein, W. L. Noorduin, H. Meekes, W. J. P. van Enckevort, R.

M. Kellogg and E. Vlieg, Angew. Chem. Int. Ed., 2008, 47, 7226-7229.

5 C. Viedma, J. E. Ortiz, T. de Torres, T. Izumi and D. G. Blackmond,
J. Am. Chem. Soc., 2008, 130, 15274-5275.

6 (a) R. E. Pincock, K. R. Wilson, J. Am. Chem. Soc., 1971, 93, 12911292; (b) R. E. Pincock, R. R. Perkins, A. S. Ma, K. R. Wilson, Science, 1971, 174, 1018-1020; (c) V. A. Avetisov, V. I. Goldanskii, S. N. Grechukha, V. V. Kuz'min, Chem. Phys. Lett., 1991, 184, 526-530. 7 See for example: (a) D. K. Kondepudi, R. J. Kaufman and N. Singh, Science, 1990, 250, 975-976; (b) D. K. Kondepudi and C. Sabanayagam, Chem. Phys. Lett., 1994, 217, 364-368; (c) D. K. Kondepudi, K. L. Bullock, J. A. Digits, J. K. Hall and J. M. Miller, J. Am. Chem. Soc., 1993, 115, 10211-10216; (d) D. K. Kondepudi, K. L. Bullock, J. A. Digits and P. D. Yarborough, J. Am. Chem. Soc., 1995, 117, 401-404; (e) D. K. Kondepudi, J. Digits and K. Bullock, Chirality, 1995, 7, 62-68; (f) C. Viedma, J. Cryst. Growth, 2004, 261, 118-121; for other recent examples of deracemization of enantiomorphic crystals of achiral substances, see Kondepudi et al. ${ }^{8}$ on the crystallization of 4,4'-dimethylchalcone and Cuccia et al. ${ }^{9}$ who have found a total of 10 organic molecules undergoing AISCA (benzil, diphenyl disulfide, benzophenone, tetraphenylethylene, guanidine carbonate, butylated hydroxytoluene, hippuric acid, ninhydrin, cytosine, and adeninium dinitrate).

8 D. J. Durand, D. K. Kondepudi, P. F. Moreira Jr. and F. H. Quina, Chirality, 2002, 14, 284-287.

9 D. T. McLaughlin, T. P. T. Nguyen, L. Mengnjo, C. Bian, Y. H. Leung, E. Goodfellow, P. Ramrup, S. Woo and L. A. Cuccia, Cryst. Growth Des., 2014, 14, 1067-1076.

10 C. Viedma, Phys. Rev. Lett., 2005, 94, 065504

11 (a) Y. Iitaka, Acta Crystallogr., 1960, 13, 35-45; (b) S. Chongprasert, S. A. Knopp and S. L. Nail, J. Pharm. Sci., 2001, 90, 1720-1728; (c) A. Dawson, D. R. Allan, S. A. Belmonte, S. J. Clark, W. I. F. David, P. A. McGregor, S. Parsons, C. R. Pulham and L. Sawyer, Cryst. Growth Des., 2005, 5, 1415-1427; (d) N. A. Tumanov, E. V. Boldyreva and H. Ahsbahs, Powder Diffr., 2008, 23, 307-316.

12 K. Ishikawa, M. Tanaka, T. Suzuki, A. Sekine, T. Kawasaki, K. Soai, M. Shiro, M. Lahav and T. Asahi, Chem. Commun., 2012, 48, 6031-6033. 13 (a) T. P. Srinivasan, R. Indirajith, R. Gopalakrishnan, J. Cryst. Growth, 2011, 318, 762-767; (b) C. Yogambal, R. Ezhil Vizhi and D. Rajan Babu, Cryst. Res. Technol., 2014, 10.1002/crat.201400151. 14 K. Srinivasan, J. Cryst. Growth, 2008, 311, 156-162.

15 F. S. Kipping and W. J. Pope, J. Chem. Soc. Trans., 1898, 73, 606617.

16 A. J. Alexander, Cryst. Growth Des., 2008, 8, 2630-2632.

17 P. S. M. Cheung and L. A. Cuccia, Chem. Commun., 2009, 13371338.

18 H. J. Simpson Jnr and R. E. Marsh, Acta Cryst., 1966, 20, 550-555. 19 H. Niinomi, H. Miura, Y. Kimura, M. Uwaha, H. Katsuno, S. Harada, T. Ujihara and K. Tsukamoto, Cryst. Growth Des., 2014, 14, 3596-3602. 20 The centrosymmetric crystals of $\alpha$-Gly, having bipyramidal morphology, is net per se chiral (crystallographic space group $P 2_{1} / \mathrm{n}$ ). However its opposite facets $(010)$ and $(0 \overline{\mathrm{I}} 0)$ are enantiotopic to each other due to the non equivalency of the methylene protons of Gly molecules located on these surfaces. I. Weissbuch, L. Addadi, Z. Berkovitch-Yellin, E. Gati, M. Lahav and L. Leiserowitz, Nature, 1984, 310, 161-164. 21 C. Viedma, J. M. McBride, B. Kahr and P. Cintas, Ang. Chem. Int. Ed., 2013, 52, 10545-10548. 

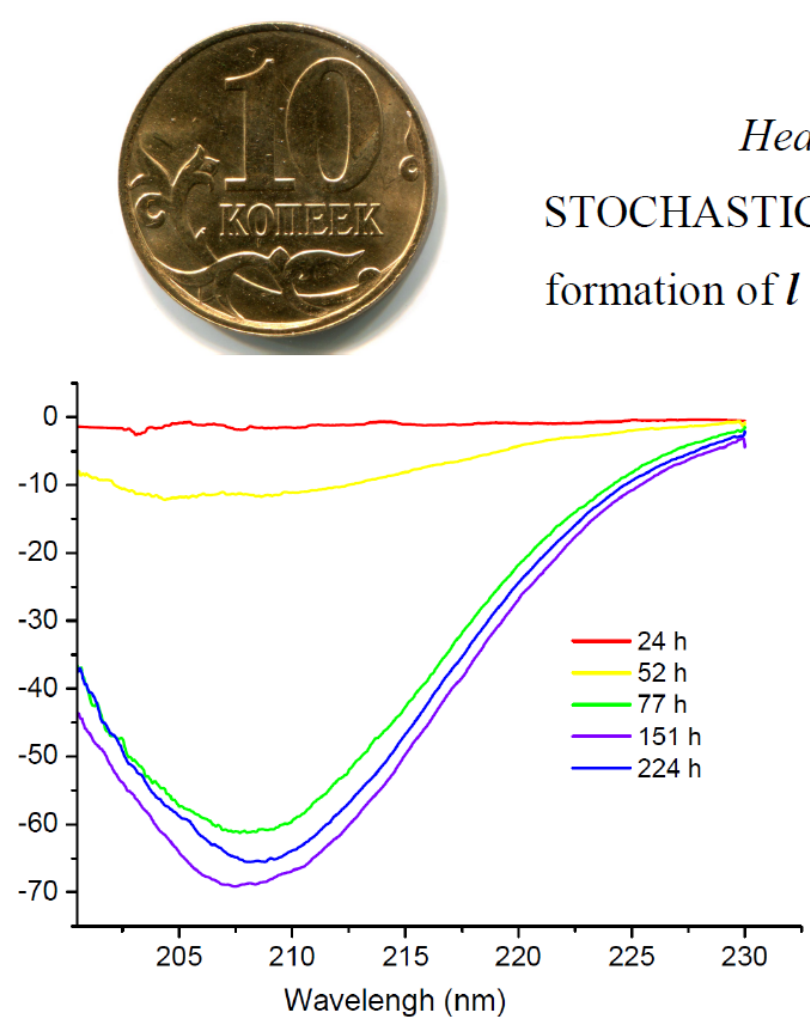

Heads or tails?

\section{STOCHASTIC and CONTROLLED}

formation of $\boldsymbol{l}$ and $\boldsymbol{d}$ chiral $\boldsymbol{\gamma}$-glycine
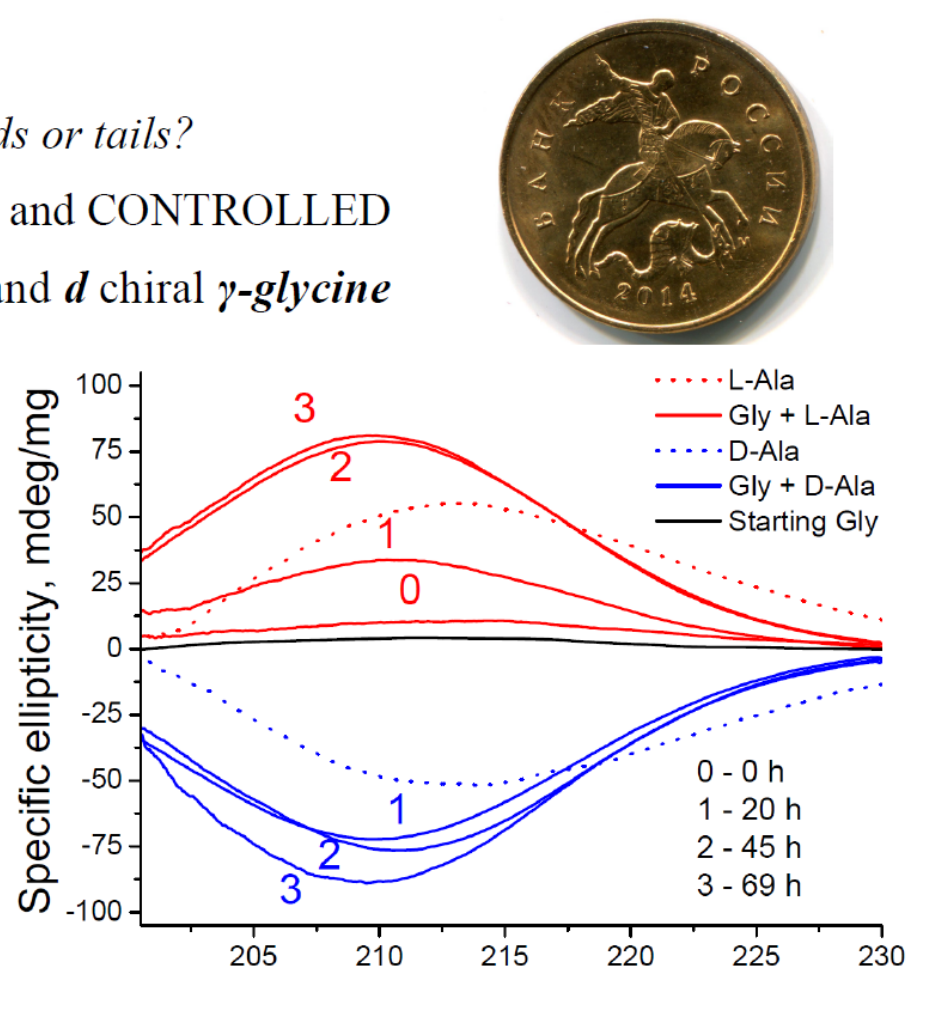

Table of Content 